\title{
Sporadic fatal insomnia in a young woman: A diagnostic challenge: Case Report
}

\author{
Karen M Moody ${ }^{*}$, Lawrence B Schonberger ${ }^{2}$, Ryan A Maddox², Wen-Quan Zou ${ }^{3}$, Laura Cracco ${ }^{3}$ and Ignazio Cali ${ }^{3}$
}

\begin{abstract}
Background: Sporadic fatal insomnia ( $\mathrm{SFI}$ ) and fatal familial insomnia (FFI) are rare human prion diseases.

Case Presentation: We report a case of a 33-year-old female who died of a prion disease for whom the diagnosis of sFI or FFI was not considered clinically. Following death of this patient, an interview with a close family member indicated the patient's illness included a major change in her sleep pattern, corroborating the reported autopsy diagnosis of sFl. Genetic tests identified no prion protein (PrP) gene mutation, but neuropathological examination and molecular study showed protease-resistant PrP (PrPres) in several brain regions and severe atrophy of the anterior-ventral and medial-dorsal thalamic nuclei similar to that described in FFI.
\end{abstract}

Conclusions: In patients with suspected prion disease, a characteristic change in sleep pattern can be an important clinical clue for identifying SFI or FFl; polysomnography (PSG), genetic analysis, and nuclear imaging may aid in diagnosis.

\section{Background}

Human prion diseases are rare, transmissible, invariably fatal neurodegenerative diseases that are characterized by the accumulation of a misfolded host protein, the prion protein, in brain tissue. They are classified into three main groups: sporadic, acquired, and genetic. Sporadic cases, with no known environmental source of infection, include sporadic Creutzfeldt - Jakob disease (CJD), the most common human prion disease, and sporadic fatal insomnia (sFI), one of the least common [1]. Acquired cases include iatrogenic CJD, acquired by medical or surgical procedures, and variant CJD, usually acquired from consuming beef products contaminated with the agent of bovine spongiform encephalopathy [1]. Genetic or familial cases are linked to a mutation on the prion protein gene, and include several subtypes of Gerstmann Sträussler Scheinker syndrome, familial CJD, and fatal familial insomnia (FFI) [2]. sFI shares a very similar phenotype to FFI, but is not associated with a mutation in the prion protein gene [3]. FFI is linked to the presence of a $\mathrm{D}$ (aspartic acid) to $\mathrm{N}$ (asparagine) variation at codon 178 (D178N) coupled with the

\footnotetext{
* Correspondence: karen.moody@dshs.state.tx.us

${ }^{1}$ Texas Department of State Health Services, 1100 West 49th Street, Austin, Texas 78756-3199, USA

Full list of author information is available at the end of the article
}

methionine at codon $129(129 \mathrm{M})$ on the mutant allele of the prion protein gene (PRNP) [4]. The presence of valine at codon $129(129 \mathrm{~V})$ coupled with the same D178N mutation is associated with a very different phenotype reminiscent of CJD [4]. sFI lacks the D178N PRNP mutation but appears to be invariably associated with methionine homozygosity at codon 129 of the PRNP, suggesting that $129 \mathrm{M}$, either coupled with the D $178 \mathrm{~N}$ mutation or present in both alleles in the absence of the mutation is a requirement for the phenotypic expression of fatal insomnia [4].

Although Kawasaki and colleagues described a probable case of sFI in 1997, the disease was definitively established in 1999 by both Mastrianni et al and Parchi et al utilizing the term sporadic fatal insomnia $[3,5,6]$. Parchi and colleagues reported five such cases in subjects between the ages of 36 and 70 years (mean 50) with duration of illness ranging from 15 to 24 months (mean 17.8) [3]. An additional ten patients have been reported in the literature as sFI, expanding the age range to $30-74$ and the disease duration to $13-73$ months [6-13].

Like FFI, sFI is characterized pathologically by thalamic atrophy and clinically by disrupted sleep, autonomic dysfunction, and motor abnormalities including myoclonus, ataxia, dysarthria, dysphagia, and pyramidal signs 
[3]. Other clinical features consist of peculiar behaviors that can be mistaken for psychotic signs. Because the patients are deprived of sleep they may display drowsiness during the day which may be described as hypersomnolence unless the abnormal nocturnal sleep pattern is recognized by electroencephalogram (EEG) and/or polysomnography (PSG). The rarity of the disease can make the diagnosis of sFI challenging. To make clinicians more aware of an unusual presentation of prion disease and to demonstrate the importance of pursuing a thorough sleep history when prion disease is being considered, we describe the clinical and pathological details of a patient whose sFI diagnosis had not been considered antemortem.

\section{Case presentation}

\section{Clinical findings}

In February 2007, the Centers for Disease Control and Prevention (CDC) and the National Prion Disease Pathology Surveillance Center (NPDPSC) notified the Texas Department of State Health Services (DSHS) of a 32-year-old woman with an 18-month history of progressive neurological symptoms suggestive of CJD. (Table 1) Based on the medical record and her neurologist, her illness began in August 2005 with attention deficits and progressive memory loss. In June 2006, she demonstrated anisocoria and bizarre behavior, including talking incoherently to herself, and she was then referred to psychiatry. On a mini-mental state examination, she scored abnormally low in the measure of attention and calculation and she had reduced ability to repeat the names of three unrelated objects [14]. Later in 2006 she was described as being in constant motion, having unfocused hand gestures, and continued difficulty with ambulation. She was reported as alert, but confused, sad, and having difficulty with her thought process. Physicians caring for the case patient discussed the possibility of several diagnoses such as viral encephalopathy, paranoid schizophrenia, and subacute sclerosing panencephalitis, yet the overall etiology remained unclear. By February 2007, the patient was unable to ambulate and became bed-bound. She continued to demonstrate bizarre behavior, inability to follow commands, and unintelligible speech. The patient expired in June 2007, 22 months after the onset of illness.

Over the course of her illness, she had EEGs, magnetic resonance imaging (MRI) studies, and cerebrospinal fluid (CSF) tests. The EEG study performed in July 2006 showed generalized slowing with bilateral periodic lateralized epileptiform discharges. A second EEG performed two to three weeks later was unsuccessful due to excessive movements of the patient. In April 2006, an MRI study was negative for intracranial abnormalities. Another MRI study was completed in February 2007
Table 1 Progression of clinical signs and symptoms

\begin{tabular}{|c|c|}
\hline Date & Clinical signs and symptoms \\
\hline August 2005 & $\begin{array}{l}\text { Onset: age 31t } \\
\text { Increased attention deficitt } \\
\text { Progressive memory losst } \\
\text { Sleep disturbance }\end{array}$ \\
\hline $\begin{array}{l}\text { February } \\
2006\end{array}$ & $\begin{array}{l}\text { Bizarre behavior } \neq \\
\text { Sitting in chair making loud incoherent noises } \neq\end{array}$ \\
\hline April 2006 & MRI - negative for intracranial abnormalitiest \\
\hline June 2006 & $\begin{array}{l}\text { Anisocoriat } \\
\text { Increased agitation } \neq \\
\text { Incoherent speech } \neq \\
\text { Balance and gait difficulties } \neq \\
\text { Talking to selft } \\
\text { Referred to psychiatry } † \\
\text { Decreased attention, registration and calculation } †\end{array}$ \\
\hline July 2006 & $\begin{array}{l}\text { Electroencephalogram (EEG) - bilateral periodic } \\
\text { epileptiform dischargest }\end{array}$ \\
\hline August 2006 & $\begin{array}{l}\text { Flat affect } \dagger \\
\text { Continued decrease in attention, registration and } \\
\text { calculationt }\end{array}$ \\
\hline $\begin{array}{l}\text { October } \\
2006\end{array}$ & $\begin{array}{l}\text { Confused } \dagger \\
\text { Constant movement }+\end{array}$ \\
\hline $\begin{array}{l}\text { November } \\
2006\end{array}$ & $\begin{array}{l}\text { Sleep enhancing medication prescribed } \neq \\
\text { Unfocused hand gestures } \dagger \\
\text { Continued difficulty with gait } \dagger\end{array}$ \\
\hline $\begin{array}{l}\text { January } \\
2007\end{array}$ & $\begin{array}{l}\text { Akathisia -inner restlessness } \\
\text { Places arms and legs in sustained posturest } \\
\text { Bizarre behaviort }\end{array}$ \\
\hline $\begin{array}{l}\text { February } \\
2007\end{array}$ & $\begin{array}{l}\text { Bed-bound } \\
\text { Unable to ambulatet } \\
\text { MRI - supratentorial parenchymal atrophy with no other } \\
\text { acute intracranial findingst }\end{array}$ \\
\hline March 2007 & $\begin{array}{l}\text { Cerebrospinal Fluid (CSF) 14-3-3 testing performed - } \\
\text { result is not elevatedt } \\
\text { Awake most of the time }\end{array}$ \\
\hline June 2007 & $\begin{array}{l}\text { Death: Age } 33 \\
\text { Duration of illness: } 22 \text { months } \\
\text { Autopsied tissue sent to National Prion Disease } \\
\text { Pathology Surveillance Center }\end{array}$ \\
\hline August 2007 & $\begin{array}{l}\text { Western blot revealed presence of abnormal protease } \\
\text { resistant prion protein } \\
\text { Immunohistochemical analysis revealed granular deposits } \\
\text { as seen in prion disease } \\
\text { MM2 SCJD, thalamic type consistent with "SFI" }\end{array}$ \\
\hline
\end{tabular}

† Information obtained from medical record

‡ Information obtained from family member

Disclaimer: The opinions expressed by authors contributing to this journal do not necessarily reflect the opinions of the Centers for Disease Control and Prevention or the institutions with which the authors are affiliated.

and it showed supratentorial parenchymal atrophy with no other acute intracranial findings. CSF studies performed in March 2007 were normal, including the amount of the 14-3-3 protein determined.

Because of the age of the patient and the potential for variant or iatrogenic CJD, in July 2007 an investigator from the DSHS (KMM) interviewed a family member to obtain additional information about the patient's travel history, past medical history, and the symptoms of the 
present illness. The patient had a history of travel outside the continental United States to Puerto Rico during 1995-96 where she had lived approximately one year. Her surgical history included two back surgeries for internal disc disruption and degenerative disc disease. An anterior lumbar discectomy with interbody fusion at L4-5 was performed in November 2000 utilizing cadaver donated bone and in August 2001 another fusion was performed at L5-S1 utilizing autologous bone. The donor of cadaver bone was pre-screened minimizing the possibility of iatrogenic transmission. There was no familial history of progressive neurological disease or dementia-like illness. The family member also confirmed the clinical history including the onset in August 2005 of progressive memory loss and, in February 2006, bizarre behavior that included the patient's sitting in a chair for hours making noises that progressively got louder.

Following preliminary autopsy results, the NPDPSC requested the DSHS re-interview the family to ask specifically about the patient's pattern of sleep. When questioned about insomnia, the family member recalled that the patient had experienced disturbed sleep at the time of her disease onset. The family member also reported that the patient's sleep pattern progressively deteriorated throughout her illness. Some nights, for example, the patient did not sleep. On other nights when she did appear to be sleeping, her sleep was intermittent. During nights that the patient did not sleep, she would roam the house at all hours, unable to calm down. By August of 2006, four hours was the maximum amount of sleep the patient would get in one stretch and at times she would go two to three days without sleep. Medications were prescribed to help her sleep but they were not beneficial.

\section{Genetic analysis}

Sequencing of the PrP gene open reading frame revealed methionine homozygosity at codon 129 , with no pathogenic mutation.

\section{Histological examination}

The mediodorsal and pulvinar thalamic nuclei along with the inferior olives showed severe neuronal loss and astrogliosis but no spongiform degeneration (SD) (Figure 1A-D and Figure 2). Astrogliosis with possible neuronal loss and superficial non-specific spongiosis affected particularly the frontal cortices while typical fine SD was present in other cortical regions, including parietal and temporal cortex (Figure 1E and $1 \mathrm{~F}$ ). With the exception of the presence of some SD in the molecular layer of the hippocampal formation, the hippocampus, basal ganglia, and cerebellum were much less affected than the cerebral cortex. Torpedoes, fusiform swellings of the Purkinje cell axons, were detectable in the granule cell layer of the cerebellum. Except in the hippocampus, where only the molecular layer was even weakly stained, immunohistochemical evaluation for the prion protein $(\operatorname{PrP})$ in the cerebral cortex demonstrated intense staining in a predominantly 'synaptic' pattern with occasional small clusters of coarse granules (Figure $1 \mathrm{G})$. Meanwhile, the basal ganglia, thalamus, and cerebellum were just faintly stained.

\section{Molecular study}

High resolution and standard Western blot analyses of the abnormal and Protease K (PK)-resistant $\operatorname{PrP}\left(\mathrm{PrP}^{\text {res }}\right)$ from 19 brain regions invariably disclosed the presence of $\mathrm{PrP}^{\text {res }}$ type 2, which, however, varied in amount according to the location (Figure 3A). Of the two main types of unglycosylated misfolded prion protein fractions used as biochemical surrogate markers in prion diseases, $\mathrm{PrP}^{\text {res }}$ type 2 protein is slightly lighter than the $\mathrm{PrP}^{\text {res }}$ type 1 as demonstrated by their electrophoretic mobility on Western blots. The highest concentration of $\operatorname{PrP}^{\text {res }}$ was observed in most cerebral cortical regions such as frontal, temporal (including entorhinal), and occipital cortices, but it was minimal in the hippocampus. Variations in amount were also detected within the same cortical region (i.e. superior, middle, and inferior frontal gyri: data not shown). Minimal amounts of $\mathrm{PrP}^{\text {res }}$ were demonstrated in the caudate nucleus and in the three thalamic nuclei examined: anterior ventral, mediodorsal, and pulvinar (Figure 3A). No $\operatorname{PrP}^{\text {res }}$ was detected in the cerebellum (Figure 3A). Detectability of $\operatorname{PrP}^{\text {res }}$ in the thalamic nuclei was enhanced either by increasing the concentration of the antibody 3F4 ten-fold or by precipitating $\operatorname{PrP}^{\text {res }}$ with sodium phosphotungstate. (Figure $3 \mathrm{~B}$ and data not shown). The ratios of the three $\operatorname{PrP}^{\text {res }}$ glycoforms, (diglycosylated, monoglycosylated, and unglycosylated) in the cerebral cortex and in the pulvinar, the only thalamic nucleus where $\operatorname{PrP}^{\text {res }}$ could be assessed accurately, were 15:42:43 and 28:38:34 respectively.

\section{Discussion and conclusions}

The clinical diagnosis of prion disease in patients with signs of neurodegenerative diseases can be aided by paying particular attention to aspects of the patient history, including the patient's travels, past surgery, neurodegenerative illnesses in the family, and to possible changes in the patient's sleep pattern. Ancillary tests for suspected prion disease often include an EEG, MRI, and the measurement of CSF 14-3-3 protein, but these tests are typically unrevealing in cases of sFI. They also include genetic testing to detect possible PRNP mutations and to determine the genotype at codon 129 of the PRNP. Either valine or methionine can normally occur at the 

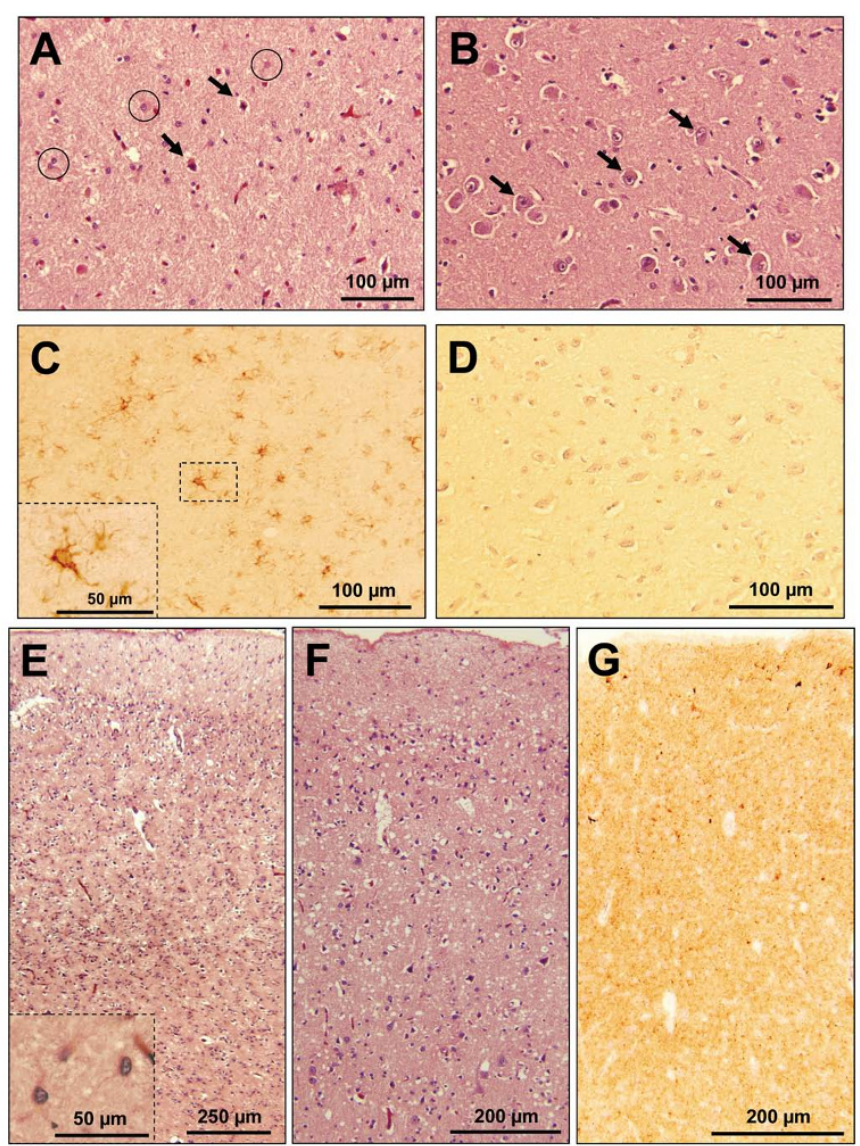

Figure 1 Histology and immunohistochemistry. A: Severe neuronal loss and astrogliosis of the mediodorsal thalamic nucleus in the present case. Neurons are indicated by arrows, reactive astrocytes by circles. B: For comparison, the same thalamic nucleus is shown in an age-matched subject without prion disease; neurons are indicated by arrows. C: Immunohistochemistry for glial fibrillary acidic protein (GFAP) reveals reactive astrocytic gliosis in the mediodorsal thalamic nucleus of the present case but not in a control subject of the same age without prion disease (D). E: Prominent astrogliosis in the frontal cortex. The inset (lower left corner) depicts three reactive astrocytes at higher magnification. F: Fine spongiform degeneration of the parietal cortex. G: Intense punctate or "synaptic" PrP immunostaining and sparse clusters of small granules in the cerebral cortex (parahippocampal gyrus; 3F4 antibody).

codon 129 of the PRNP and this polymorphism can strongly influence many aspects of human prion disease, including the disease phenotype and the susceptibility of a host to a prion infection. If FI is a diagnostic consideration, potentially helpful additional tests include PSG and nuclear imaging to demonstrate reduced tracer uptake in the thalamus $[15,16]$. Finally, pathological examination of brain tissue at autopsy is the definitive way to confirm the presence and type of prion disease.

For the patient described in this report, her long duration of illness and young age at onset are unusual for the most common subtype of prion disease, sporadic CJD [17]. Other forms of CJD were considered but determined to be extremely unlikely. Although this young patient showed signs of psychiatric illness at the beginning of her disease consistent with variant CJD (vCJD), these signs did not precede her noticeable deficits in attention and memory and she had not traveled to any country where transmission of $\mathrm{vCJD}$ was known to occur.

Iatrogenic CJD has been associated with a number of medical procedures. However, it is not known to be linked with receipt of a bone transplant. Furthermore, the donor of the bone transplant received by our patient had been pre-screened providing greater assurance of the absence in the donor of an infectious or neurological illness [18]. This patient also had no family history of neurodegenerative illness.

The history of insomnia was not in the medical chart nor was a sleep study or nuclear imaging study performed [7]. The neuropathological studies of the brain tissue demonstrated atrophy of the patient's thalamus, the neuropathological signature of both FFI and sFI, which then prompted the interview with a family member about the patient's sleep patterns. The diagnosis of sFI was made at autopsy based on the pathological 


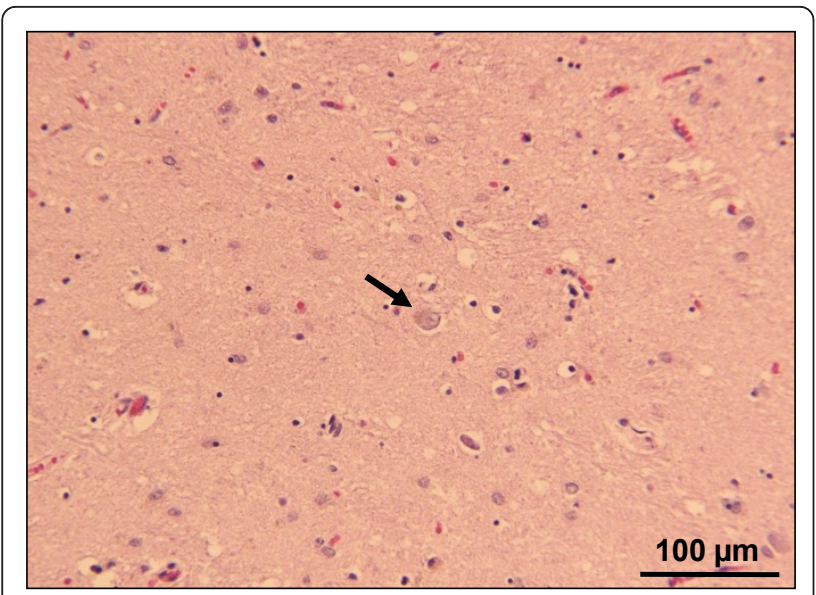

Figure 2 Hematoxylin-eosin staining of the mediodorsal thalamic nucleus. As seen in the present case, the hematoxylineosin staining of the mediodorsal thalamic nucleus also shows severe neuronal loss in a fatal familial insomnia (FFI) control case. The arrow indicates a thalamic neuron.

evidence and the results of the genetic testing indicating the absence of a PRNP mutation. The history of progressively worsening insomnia is characteristic of sFI and underscores the importance of taking a careful history of possible changes in the patient's sleep pattern when evaluating an illness suggestive of a prion disease, particularly if the illness exceeds 12 months in duration.
The consistency of the association of sleep-wake disturbances with FFI and sFI has been recently challenged. Zarranz et al have examined the sleep disorder in 23 symptomatic carriers of the D178N mutation both homozygous for methionine (D178N-129MM) and methionine/valine heterozygous (D178N-129MV) [19]. Eleven of these patients were reported not to have insomnia. However, only two of these patients had a PSG study that is essential to rule out the presence of insomnia often difficult to detect clinically especially in the D178N-129MV patients. In both these patients PSG examination did reveal a severe sleep disorder compatible with FFI. The authors also claim that the clinicopathological phenotype was that of CJD rather than FFI in eleven of these 23 patients. However, autopsy examination of the brain essential to exclude the thalamic atrophy characteristic of FFI was carried out in only four of these eleven subjects and the histology of the thalamus is not described.

Combined, the studies of Landolt et al, Taratuto et al and La Morgia et al raise the issue of a wider prevalence of sleep disorder in prion diseases that deserves further study [20-22]. Landolt et al reported the presence of sleep-wake symptoms in all of seven patients with proven SCJD. However, the histology of the thalamus was examined in only four of the seven subjects and in a semi-quantitative fashion which regrettably did not include the assessment of the neuronal loss and the

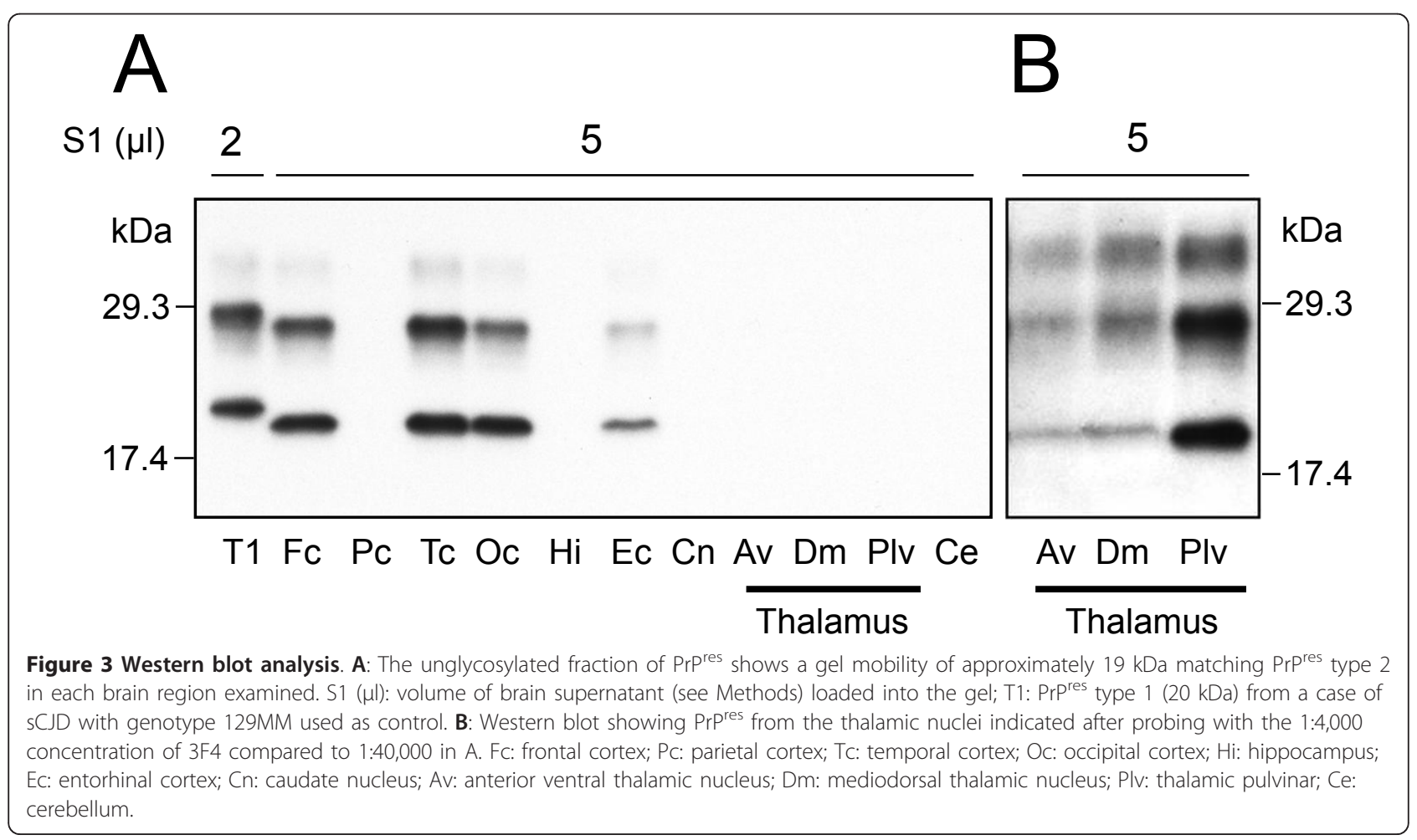


study of the thalamus in cases of sFI and FFI as positive controls of degree of thalamic atrophy. Furthermore, impairment of the autonomic system, a prominent component of the FFI phenotype, was not investigated in these cases [20]. These considerations are relevant also to the report of Taratuto et al of the presence of sleep impairment similar to that of FFI in a subject with the E200K-129MM mutation [21]. However, in this case the thalamus was fairly severely involved with gliosis and neuronal loss. Finally, La Morgia et al observed a sleep disorder similar to that of FFI and sFI in a case of sCJDVV2 with severe thalamic involvement by $\mathrm{H}-\mathrm{MR}$ spectroscopy and detectable neuronal loss at histological examination [22].

Compared to the previous reports of sFI, the present case shows at least four major similarities: i) the presence of type $2 \mathrm{PrP}^{\text {res}}$; ii) greater amount of $\operatorname{PrP}^{\text {res }}$ in the cerebral cortex compared to that in the sub cortical regions [3,10]; iii) glycoform ratios in the cerebral cortex and pulvinar that differ from that reported in FFI; and iv) no detectable $\operatorname{Pr} \mathrm{P}^{\text {res }}$ in the cerebellum. These findings along with the prominent thalamic atrophy and clinical evidence of sleep impairment definitely justify the classification of the present case as sFI.

Recently a case of alleged sFI has been reported showing the presence of $\mathrm{PrP}^{\text {res }}$ type 1 (rather than type 2 as in the present and other cases of sFI); the largest amount of $\operatorname{PrP}^{\text {res }}$ in the mediodorsal thalamic nucleus, and a glycoform ratio characterized by the relative prevalence of the diglycosylated $\operatorname{PrP}^{\text {res }}$ isoform similar to that of FFI [23]. If confirmed, this case indicates that, as in SCJD in general, occasional and unexplained phenotypic variations have to be expected in sFI. Finally, the severe neuronal loss of the anterior ventral and mediodorsal thalamic nuclei which contained relatively low amounts of $\mathrm{PrP}^{\mathrm{res}}$ raises the issue of whether other isoforms of neurotoxic PrP such as protease-sensitive $\operatorname{PrP}$ are present in the thalamic nuclei in sFI.

\section{Materials and methods} Reagents and antibodies

Proteinase K (PK), sodium phosphotungstic acid (NaPTA), N-Lauroylsarcosine sodium salt (sarkosyl), and phenylmethylsulfonyl fluoride (PMSF) were purchased from Sigma Chemical Co. (St. Louis, MO, USA). Benzonase nuclease was purchased from Novagen (Gibbstown, NJ, USA). Reagents for enhanced chemiluminescence (ECL plus) and the horseradish peroxidaseconjugated antibody were produced by Amersham Biosciences (Piscataway, NJ, USA). The 3F4 monoclonal antibody (mAb) was used against PrP residues 106-110 [24].

\section{Brain samples}

Human brain tissues were obtained at autopsy and stored at $-80^{\circ} \mathrm{C}$. Samples were taken from 19 different brain regions: superior, middle, and inferior gyri of the frontal and temporal cortices, the middle gyrus of the parietal cortex, visual and non-visual occipital cortices, entorhinal and hippocampal cortices, basal ganglia (caudate nucleus, putamen, globus pallidus), substantia nigra, thalamus (anterior ventral, mediodorsal and pulvinar nuclei), and cerebellum (hemispheres).

\section{Molecular genetics}

DNA was extracted from frozen brain tissues in all the cases, and genotypic analysis of PRNP coding region was performed as described [25].

\section{Histopathology and PrP immunohistochemistry}

Histopathology and $\mathrm{PrP}$ immunohistochemistry were performed as described [26]. The sections were deparaffinized, rehydrated, and immersed in TBS-T. Endogenous peroxidase was blocked by Envision Flex Peroxidase Blocking Reagent (Dako) for ten minutes and washed. For 3F4 immunostaining only, sections were completely immersed in $1.5 \mathrm{mmol} / \mathrm{L}$ hydrochloric acid and microwaved for fifteen minutes. The slides were either incubated with GFAP 1:12000 (Sigma-Aldrich, St. Louis, $\mathrm{MO}$ ) or 3F4 1:750 for one hour, washed, and incubated with Envision Flex/HRP polymer for 30 minutes (Dako). Envision Flex DAB (Dako) was used to visualize the immunoreactivity.

\section{Preparation of tissue homogenates and proteinase $\mathrm{K}$ digestion}

Brain homogenates $(10 \% \mathrm{w} / \mathrm{v})$ were prepared in lysis buffer with $100 \mathrm{mM}$ TRIS- $\mathrm{HCl}(100 \mathrm{mM} \mathrm{NaCl}, 10 \mathrm{mM}$ EDTA, 0.5\% NP-40, 0.5\% sodium deoxycholate, $100 \mathrm{mM}$ Tris- $\mathrm{HCl}, \mathrm{pH} 8.0)$ and centrifuged at $1000 \times g$ for five minutes to collect the supernatant (S1). Homogenates were incubated with $5 \mathrm{Unit} / \mathrm{ml}(\mathrm{U} / \mathrm{ml})$ PK $[48$ Units $/ \mathrm{mg}$ specific activity at $37^{\circ} \mathrm{C}$, with $1 \mathrm{U} / \mathrm{ml}$ equal to $20.8 \mu \mathrm{g} /$ $\mathrm{ml} \mathrm{PK}]$ at $37^{\circ} \mathrm{C}$ for one hour, and then stopped by the addition of $2 \mathrm{mM}$ PMSF. Samples were mixed in an equal volume of $2 \times$ sample buffer (6\% SDS, $5 \% \beta$-mercaptoethanol, 20\% glycerol, $4 \mathrm{mM}$ EDTA, $125 \mathrm{mM}$ Tris$\mathrm{HCl}, \mathrm{pH}$ 6.8) and boiled for ten minutes.

\section{Enrichment of PrP by sodium phosphotungstate (NaPTA) precipitation}

Precipitation of PrP aggregates by NaPTA was conducted as described with minor modification [27]. Briefly, 10\% (w/v) homogenates from brain were prepared in PBS lacking $\mathrm{Ca}^{2+}$ and $\mathrm{Mg}^{2+}$. The samples were centrifuged at $1000 \times g$ for 10 minutes at $4^{\circ} \mathrm{C}$ and 
$0.5 \mathrm{ml}$ of supernatant was then mixed with an equal volume of $4 \%(\mathrm{w} / \mathrm{v})$ sarkosyl prepared in PBS, $\mathrm{pH} 7.4$, and incubated for 10 minutes at $37^{\circ} \mathrm{C}$. Each sample was adjusted to final concentrations of $50 \mathrm{U} / \mathrm{ml}$ benzonase and $1 \mathrm{mmol} / \mathrm{L} \mathrm{MgCl}_{2}$ and incubated for 30 minutes at $37^{\circ} \mathrm{C}$. Aliquots were adjusted with $81.3 \mu \mathrm{l}$ of a stock solution containing $4 \%(\mathrm{w} / \mathrm{v}) \mathrm{NaPTA}$ and $170 \mathrm{mmol} / \mathrm{L}$ $\mathrm{MgCl}_{2}$ at a final concentration of $0.3 \%(\mathrm{w} / \mathrm{v}) \mathrm{NaPTA}$. Samples were incubated at $37^{\circ} \mathrm{C}$ for 30 minutes before centrifugation at $16,000 \times g$ for 30 minutes. After isolation of the supernatant, the pellet was resuspended in $0.1 \%$ sarkosyl prepared in PBS, pH 7.4 for Western blotting.

\section{Western blotting}

Proteins were separated by both non-commercial, homemade 15\% Tris- $\mathrm{HCl}, 20 \mathrm{~cm}$-long SDS-PAGE gels and $15 \%$ Tris- $\mathrm{HCl}$ Criterion precast gels (Bio-Rad, Hercules, CA). Proteins were then transferred to PVDF membrane (Immobilon-P; Millipore) for two hours at $60 \mathrm{~V}$. The 3F4 antibody was incubated for two hours at room temperature $(1: 40,000$ and 1:4,000). After incubation with horseradish peroxidase-conjugated sheep anti-mouse IgG at 1:3000, the PrP bands were visualized on Kodak film (Eastman- Kodak, Rochester, NY) by the ECL Plus (GE Healthcare, Fairfield, CT) as described by the manufacturer. Densitometric analysis was performed with UN-SCAN-IT gel 5.1.

\section{Consent}

Written informed consent was obtained from the patient's next of kin for publication of this case report. A copy of the written consent is available for review by the Editor-In-Chief of this journal.

\section{Acknowledgements \\ Funding disclosures \\ Ms. Moody reports no disclosures \\ Dr. Schonberger reports no disclosures \\ Mr. Maddox reports no disclosures \\ Dr. Zou reports no disclosures \\ Dr. Cracco reports no disclosures \\ Mr. Cali reports no disclosures}

The authors would like to acknowledge and thank the following for their contribution to this manuscript. Dr. Pierluigi Gambetti (National Prion Disease Pathology Surveillance Center, Director, expert technical assistance) Ms. Sally Berri (National Prion Disease Pathology Surveillance Center, Center Manager, editing and technical assistance), Ms. Janis Blevins (National Prion Disease Pathology Surveillance Center, support and guidance with data collection), Ms. Laura Tabony (Texas Department of State Health Services, editing and general support), Dr. Marilyn Felkner (Texas Department of State Health Services editing and general support), and Diane Kofskey (National Prion Disease Pathology Surveillance Center, technical assistance).

\section{Author details}

'Texas Department of State Health Services, 1100 West 49th Street, Austin, Texas 78756-3199, USA. ${ }^{2}$ Centers for Disease Control and Prevention, Atlanta,
Georgia, USA. ${ }^{3}$ National Prion Disease Surveillance Center, Case Western Reserve University, Cleveland, Ohio 44106-7288, USA.

\section{Authors' contributions}

KMM conceived of the study, participated in the design, drafting, and revision of manuscript, conducted interviews and provided intellectual content. LBS made substantial contributions in the analysis and interpretation of data and was involved with drafting and revising it critically for important intellectual content. RAM contributed interpretation of data and critical revision of the manuscript. WQZ conceived of the study, contributed to analysis and interpretation of data, and critical revision of the manuscript for important intellectual content. LC contributed interpretation of data and critical revision of the manuscript. IC participated in acquisition of data, analysis and interpretation of data, drafting and revising the manuscript. All authors read and approved the final manuscript.

\section{Declaration of Competing interests}

The authors declare that they have no competing interests.

Received: 25 April 2011 Accepted: 31 October 2011

Published: 31 October 2011

\section{References}

1. Will RG, Alpers MP, Dormont D, Schonberger LB: Infectious and sporadic prion diseases. In Prion Biology and Diseases.. 2 edition. Edited by: Prusiner S. New York: Cold Spring Harbor Laboratory Press; 2004:629-71.

2. Kong Q, Surewicz WK, Petersen RB, Zou WQ, Chen SG, Gambetti P, Parchi P, Capellari S, Goldfarb L, Montagna P, Lugaresi E, Piccardo P, Ghetti B: Inherited prion disease. In Prion biology and diseases.. 2 edition. Edited by: Prusiner S. New York: Cold Spring Harbor Laboratory Press; 2004:673-776.

3. Parchi P, Capellari S, Chin S, Schwarz HB, Schecter NP, Butts JD, Hudkins P, Burns DK, Powers JM, Gambetti P: A subtype of sporadic prion disease mimicking fatal familial insomnia. Neurology 1999, 52:1757-1763.

4. Goldfarb LG, Petersen RB, Tabaton M, Brown P, LeBlanc AC, Montagna P, Cortelli P, Julien J, Vital C, Pendelbury WW, Haltia M, Wills PR, Hauw JJ, McKeever PE, Monari L, Schrank B, Swergold GD, Autilio-Gambetti L, Gajdusek DC, Lugaresi E, Gambetti P: Fatal familial insomnia and familial Creutzfeldt-Jakob disease: disease phenotype determined by a DNA polymorphism. Science 1992, 258:806-808.

5. Kawasaki K, Wakabayashi K, Kawakami A, Higuchi M, Kitamoto T, Tsuji S, Takahashi H: Thalamic form of Creutzfeldt-Jakob disease or fatal insomnia? Report of a sporadic case with normal prion protein genotype. Acta Neuropathol 1997, 93:317-322

6. Mastrianni JA, Nixon R, Layzer R, Telling GC, Han D, DeArmond SJ, Prusiner SB: Prion protein conformation in a patient with sporadic fatal insomnia. N Engl J Med 1999, 340:1630-1638.

7. Scaravilli F, Cordery RJ, Kretzschmar H, Gambetti P, Brink B, Fritz V, Temlett J, Kaplan C, Fish D, An SF, Schulz-Schaeffer WJ, Rossor MN: Sporadic fatal insomnia: a case study. Ann Neurol 2000, 48:665-668.

8. Yamashita M, Yamamoto T, Nishinaka K, Udaka F, Kameyama M, Kitamoto T: Severe brain atrophy in a case of thalamic variant of sporadic CJD with plaque-like PrP deposition. Neuropathology 2001, 21:138-143.

9. Hamaguchi T, Kitamoto T, Sato T, Mizusawa H, Nakamura Y, Noguchi M, Furukawa Y, Ishida C, Kuji I, Mitani K, Murayama S, Kohriyama T, Katayama S, Yamashita M, Yamamoto T, Udaka F, Kawakami A, Ihara Y, Nishinaka T, Kuroda S, Suzuki N, Shiga Y, Arai H, Maruyama M, Yamada M: Clinical diagnosis of MM2-type sporadic Creutzfeldt-Jakob disease. Neurology 2005, 64:643-648.

10. Piao YS, Kakita A, Watanabe H, Kitamoto T, Takahashi H: Sporadic fatal insomnia with spongiform degeneration in the thalamus and widespread PrPSC deposits in the brain. Neuropathology 2005, 25:144-149.

11. Hirose $K$, Iwasaki $Y$, Izumi M, Yoshida M, Hashizume $Y$, Kitamoto $T$, Sahashi K: MM2-thalamic-type sporadic Creutzfeldt-Jakob disease with widespread neocortical pathology. Acta Neuropathol 2006, 112:503-511.

12. Capellari S, Parchi P, Cortelli P, Avoni P, Casadei GP, Bini C, Baruzzi A, Lugaresi E, Pocchiari M, Gambetti P, Montagna P: Sporadic fatal insomnia in a fatal familial insomnia pedigree. Neurology 2008, 70:884-885.

13. Mehta LR, Huddleston BJ, Skalabrin EJ, Burns JB, Zou WQ, Gambetti P, Chin SS: Sporadic fatal insomnia masquerading as a paraneoplastic cerebellar syndrome. Arch Neurol 2008, 65:971-973. 
14. Folstein MF, Folstein SE, McHugh PR: "Mini-mental state". A practical method for grading the cognitive state of patients for the clinician. $J$ Psychiatr Res 1975, 12:189-198.

15. Barash JA: Clinical features of sporadic fatal insomnia. Rev Neurol Dis 2009, 6:E87-93.

16. Cortelli P, Perani D, Parchi P, Grassi F, Montagna P, De Martin M, Castellani R, Tinuper P, Gambetti P, Lugaresi E, Fazio F: Cerebral metabolism in fatal familial insomnia: relation to duration, neuropathology, and distribution of protease-resistant prion protein. Neurology 1997, 49:126-133

17. Gambetti P, Kong Q, Zou W, Parchi P, Chen SG: Sporadic and familial CJD: classification and characterisation. Br Med Bull 2003, 66:213-239.

18. Brown P, Brandel JP, Preece M, Sato T: latrogenic Creutzfeldt-Jakob disease: the waning of an era. Neurology 2006, 67:389-393.

19. Zarranz JJ, Digon A, Atares B, Rodriguez-Martinez AB, Arce A, Carrera N, Fernandez-Manchola I, Fernandez-Martinez M, Fernandez-Maiztegui C, Forcadas I, Galdos L, Gómez-Esteban JC, Ibáñez A, Lezcano E, López de Munain A, Martí-Massó JF, Mendibe MM, Urtasun M, Uterga JM, Saracibar N, Velasco F, de Pancorbo MM: Phenotypic variability in familial prion diseases due to the D178N mutation. J Neurol Neurosurg Psychiatry 2005, 76:1491-1496

20. Landolt HP, Glatzel M, Blattler T, Achermann P, Roth C, Mathis J, Weis J, Tobler I, Aguzzi A, Bassetti CL: Sleep-wake disturbances in sporadic Creutzfeldt-Jakob disease. Neurology 2006, 66:1418-1424

21. Taratuto AL, Piccardo P, Reich EG, Chen SG, Sevlever G, Schultz M, Luzzi AA, Rugiero M, Abecasis G, Endelman M, Garcia AM, Capellari S, Xie Z, Lugaresi E, Gambetti P, Dlouhy SR, Ghetti B: Insomnia associated with thalamic involvement in E200K Creutzfeldt-Jakob disease. Neurology 2002, 58:362-367.

22. La Morgia C, Parchi P, Capellari S, Lodi R, Tonon C, Rinaldi R, Mondini S, Cirignotta F: 'Agrypnia excitata' in a case of sporadic Creutzfeldt-Jakob disease WV2. J Neurol Neurosurg Psychiatry 2009, 80:244-246.

23. Priano L, Giaccone G, Mangieri M, Albani G, Limido L, Brioschi A, Pradotto L, Orsi L, Mortara P, Fociani P, Mauro A, Tagliavini F: An atypical case of sporadic fatal insomnia. J Neurol Neurosurg Psychiatry 2009, 80:924-927.

24. Zou WQ, Langeveld J, Xiao X, Chen S, McGeer PL, Yuan J, Payne MC, Kang HE, McGeehan J, Sy MS, Greenspan NS, Kaplan D, Wang GX, Parchi P, Hoover E, Kneale G, Telling G, Surewicz WK, Kong Q, Guo JP: PrP conformational transitions alter species preference of a PrP-specific antibody. J Biol Chem 2010, 285:13874-13884.

25. Parchi P, Castellani R, Capellari S, Ghetti B, Young K, Chen SG, Farlow M, Dickson DW, Sima AA, Trojanowski JQ, Petersen RB, Gambetti P: Molecular basis of phenotypic variability in sporadic Creutzfeldt-Jakob disease. Ann Neurol 1996, 39:767-778.

26. Cali I, Castellani R, Yuan J, Al-Shekhlee A, Cohen ML, Xiao X, Moleres FJ, Parchi P, Zou WQ, Gambetti P: Classification of sporadic Creutzfeldt-Jakob disease revisited. Brain 2006, 129:2266-2277.

27. Wadsworth JD, Joiner S, Hill AF, Campbell TA, Desbruslais M, Luthert PJ, Collinge J: Tissue distribution of protease resistant prion protein in variant Creutzfeldt-Jakob disease using a highly sensitive immunoblotting assay. Lancet 2001, 358:171-180.

\section{Pre-publication history}

The pre-publication history for this paper can be accessed here: http://www.biomedcentral.com/1471-2377/11/136/prepub

doi:10.1186/1471-2377-11-136

Cite this article as: Moody et al:: Sporadic fatal insomnia in a young woman: A diagnostic challenge: Case Report. BMC Neurology 2011 11:136.

\section{Submit your next manuscript to BioMed Central and take full advantage of:}

- Convenient online submission

- Thorough peer review

- No space constraints or color figure charges

- Immediate publication on acceptance

- Inclusion in PubMed, CAS, Scopus and Google Scholar

- Research which is freely available for redistribution

Submit your manuscript at www.biomedcentral.com/submit
Ciomed Central 